\title{
Psychosocial and Economic Variables as Correlates of Adults' Participation into Sandwich Educational Programs in Osun State, Nigeria
}

\author{
Waliyi Olayemi Aransi \\ 'Faculty of Education, Department of Adult Education, University of Ibadan, Ibadan, Nigeria.
} Email:omoaransi@yahoo.comTel +2347030251269

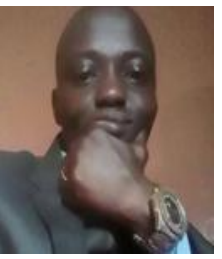

\begin{abstract}
The paper examined psychosocial and economic variables as correlates of adult learners' participation in sandwich educational programs in Osun State, Nigeria. In light of this, three research objectives and questions were formulated while two research hypotheses were enumerated. The descriptive research design was adopted and a simple percentage, as well as independent t-test, was used for data analysis. One-hundred and eight (108) participants were selected from both degree and postgraduate segments of the National Teachers Institute (NTI) programs situated in Ikire of Irewole Local Government Area of Osun State with the aid of stratified random sampling technique. The research instrument tagged Psychosocial and Economic Variables Questionnaire (PEVQ) was employed to elicit prominent information from the participants. The findings revealed that psychological, societal and economic variables contributed to adult learners' decision-making process not only to participate into sandwich educational programs but also to persist in the programs till the completion stage. And that there is no significant difference in the extent to which psychological and economic variables influence adult learners to participate in sandwich educational programs on the basis of their gender traits. On the societal variables, it showed that there is a significant difference in the role societal variables played on the basis of gender. Besides, it indicated that there is no significant different in the extent to which psychological, societal and economic variables influence adult participation into educational programs on the basis of employment status. Recommendations including the application of the participatory approach, employment of andragogy principles and provision of financial aid for participants of sandwich educational programs among others were suggested.
\end{abstract}

Keywords: Psychosocial, Economic, Correlate, Andragogy, Adults participation, Sandwich educational programs.

Citation | Waliyi Olayemi Aransi (2019). Psychosocial and Economic Variables as Correlates of Adults' Participation into Sandwich Educational Programs in Osun State, Nigeria. Journal of Education and e-Learning Research, 6(3): 107-115.

History:

Received: 8 March 2019

Revised. 12 April 2019

Revised: 12 April 2019

Accepted. 16 May 2019

Published: 29 July 2019

Licensed: This work is licensed under a Creative Commons Attribution 3.0 License $(\mathrm{cc}) \mathbf{B}$

Publisher: Asian Online Journal Publishing Group
Funding: This study received no specific financial support

Competing Interests: The author declares that there are no conflicts of interests regarding the publication of this paper.

Transparency: The author confirms that the manuscript is an honest, accurate, and transparent account of the study was reported; that no vital features of the study have been omitted; and that any discrepancies from the study as planned have been explained.

Ethical: This study follows all ethical practices during writing.

\section{Contents}

1. Introduction 


\section{Contribution of this paper to the literature}

This study contributes to the existing literature by identifying and examining some of the preeminent components of psychosocial and economic indicators vis-à-vis adults' enrolment into sandwich educational programs.

\section{Introduction}

Adult education, according to United Nations Educational, Scientific and Cultural Organization (UNESCO) is described as 'the entire body of organized educational processes, whatever the content, level and method, whether formal or otherwise, whether they prolong or replace initial education in schools, colleges and universities as well as in apprenticeship, whereby persons regarded as adult by the society to which they belong develop their abilities, enrich their knowledge, improve their technical or professional qualifications or turn them in a new direction and bring about changes in their attitudes or behavior in the twofold perspective of full personal development and participation in balanced and independent social, economic and cultural development'. To Organization for Economic Co-operation and Development (OECD), Adult education refers to any learning activity or program deliberately designed by a providing agent to satisfy any learning need or interest that may be experienced at any stage in his or her life by a person who is over the statutory leaving age and whose principal activity is no longer in education. It spans non-vocational, vocational, general, formal and non-formal studies as well as education with a collective social purpose. This depicts that adult education is one of a viable tools for development of skills and competences needed by the adults. In the same vein, it would serve as a means of overcoming challenges faced by vulnerable social groups such as early school leavers, low skill adults in literacy, numeracy and Information and Communication Technology (ICT) among others.

However, aside from chronological age and the legal description of adulthood, adult could also be determined through social and psychological criteria. From a social criterion perspective, adulthood can be linked to the social roles one is expected to assume, like those of an employee such as working full-time or otherwise, a spouse, a parent, a boss and the rest. From a psychological school of thought, an adult is expected to manage the various forms of conflicts among which are intimacy and isolation, generativity and stagnation, as well as ego integrity and despair. Kokkos (2005) acknowledged that an individual may be considered as an adult not only on the ground of being in a state of adulthood but also exhibit elements of maturity and self-determination. Rogers and Horrocks (2010) identified sense of perspective, full development and maturity, as well as level of autonomy as three main clusters for determining adulthood. This indicates that what differentiates adult education from childhood education is the extent to which these three clusters of ideas are taken into cognizance when planning and formulating an educational program. This is because, prevalence of full development, exploitation of talents, exhibition of interests, presence of sense of perspective and self-confidence during adulthood enhance them to actively involved in educational programs which would in turn stimulate the attainment of aims and objectives of the programs as oppose lack of awareness of one's abilities, interests and perspective as well as relinquishment of responsibilities that may common among childhood education.

In the light of this, adult educator, that is, facilitator may encounter challenges in the course of teachinglearning interaction in the adult classroom, as they are highly heterogeneity in nature with respect to developmental stage, age group and life transitions. According to Kokkos (2005) adults have some features which could either promote or impede their ambition to participate in an organized educational program. Report of Train Intercultural Mediators for a Multicultural Europe Project Partnership (2016) revealed multidimensional attributes of adult as follows; firstly, they have established goals prior to their entry in to educational process. This is to say that their decision to participate in an educational programs may be a function of attainment of variety of setting goals such as professional advancement, fulfilment of social roles (like attending parenting classes), personal development and status improvement with respect to self-actualization among others. Secondly, it is believed that adults have more life experiences which they are taking to the educational programs compared with the average typical learner. This may constitute either a strength or a barrier to a new learning experience. It is a strength if it serves as a foundation upon which new knowledge is built. While, it turns to a barrier if it is being used by adult not only to form set of values and beliefs, but also to resist the acceptance of new knowledge, skills and learning experiences which are offered to them in any organized educational program. Thirdly, adults usually developed their preferred learning style such that if the program is designed in such a way that their learning styles is not accommodated, this would hinder the rate at which they assimilate the content of the learning material and might frustrate them to exiting from the program.

It is on this note that made (Rogers and Horrocks, 2010) to submit that change agents need to remember the prevalence of individual difference including learning styles during teaching and learning interaction. Fourthly, they have a tendency for active participation and expect to be actively involved in the learning process. They need active rather than passive learning experiences and demand to be treated as mature and responsible individuals. In as much as, adult enter sandwich educational program with specific goals, they are more likely to challenge the educational content and /or the learning methods used in the system. Fifthly, they face barriers to learning as a result of poor organization of the educational activity, the learners' social obligations and responsibilities, intrinsic barriers that relate to pre-existing knowledge and values, as well as barriers that stem from psychological factors. And, finally, adults have potential to develop defense and withdrawal mechanisms which may arise when internal barriers lead to resistance to accept new set of information and knowledge and to redefine previous knowledge, values and habits.

There is no gainsaying that adult face several obstacles before or during their participation into educational programs, this may slow down learning and thereby leading to his/her exiting from the program early enough before completion time. It is on this note that made (Kokkos, 2005) to concur that obstacles to adult learners' participation could either be external or internal. He affirmed that internal ones play a crucial role in the learner's decision on whether or not to remain in the educational program and whether or not to invest in learning. This is in agreement with the submission made by Rogers and Horrocks (2010) that internal barriers play a key role in the process of adult learning which could be derived from both pre-existing knowledge and emotional factors of the 
concerned adult. As a result of this, adult may be found defending and protecting their pre-existing knowledge due to the fact that it costs them emotional capital. Also, emotional factors are multi-dimensional in nature which manifest in terms of negative self-image, fear of failure, fear of criticism, fear of disappointing oneself and/or others and fear of the unknown. In addition, the anxiety experienced by adults may relate to situations that arise as part of the social or situation-specific roles they assume at a given time which include being a parent, unemployed to mention a few.

In another development, Abdullah et al. (2009) disaggregate barriers to participate in educational program into situational, institutional and dispositional. Situational barriers entail those that arise from one's situation at a given time such as lack of time, lack of money and lack of childcare, institutional barriers encompass those practices and procedures that exclude or discourage adults from participating in learning activities such as poor organization, facilities, schedule, location, cost, ownership among others, while dispositional barriers contain those related to attitudes and self-perceptions about oneself as a learner. This has made (Kasworm, 2003) to delineate five areas of self and society that influence adults to navigate through their collegiate experience which are work responsibilities, family and other significant responsibilities, financial responsibilities, community responsibilities, student role responsibilities, and responsibilities to self. It is therefore possible that the execution of the student role responsibilities by the adults might be conflictual with other responsibilities which could in turn hinder their persistence. Moreover, even if they enroll and persist in the academic program, they may not have time to socialize on campus due to several external factors competing for their time and energy such as jobs, family, and on-going commitments to their community at large.

Quality and relevance of curriculum, quality of higher adult education available, adequacy of instructional aids and methods as well as learning environment are some of the identified institutional factors to adult participation in educational process. In terms of quality of curriculum, it is a known fact that curriculum precedes instruction most especially in formal adult education program. However, curriculum is critical in motivating adults to participate in any learning endeavors. In higher adult education, curriculum is transposed into syllabus which contains specific information about a course of study, including goals and objectives; an outline and summary of topics to be covered in the course; schedule of class meeting times and class activities; expectations; and evaluation criteria-- rubrics or grading standards among others. A program could be of high quality when the curriculum meets both professional and non-professional needs of the adults' participants. This is due to the fact that adult may easily felt irritated and turned off when a syllabus is not geared toward their felt needs and expectations, which they see as a waste of their precious resources like time and money. We can deduced that learning can be influenced by what it brings to the learners, that is, either satisfaction or annoyance. This is because, a thing learned is strengthened if the result is satisfying by the learners, and weakened if the result is annoying.

Moreover, a curriculum that lacks relevance and pragmatism may be considered abstract, dull, and even theoretical in nature. This is consequence upon the fact that adult have a practical reason for their learning and they want to learn something that they can apply immediately in their day-to-day exercises. Therefore, they prefer problem-focused and hands-on-learning activities that are relevant to their immediate needs. As claimed by Wlodkowski (2003) relevance leads to what human beings generally experience as interest and when adult feel interested in what they learn, their motivation increases towards more meaningful learning. In other words, adult prefer learning experiences that are experiential in nature. This may not be feasible, if the curriculum lacks needed ingredient to enhance learners' intrinsic motivation in terms of failure to show the adults the connection between the course and their interests. Also, perception of individual adult towards the quality of higher education available in the society is useful to decide whether to partake in educational activities or not. This is because, quality of higher education can be determined from both resources and performance point of view. Classification of higher education quality according to Koslowski (2006) revealed the components of quality like transcendent quality which entails result of reputation of higher education and expertise of academic staff, manufacturing-based quality which ensures that the service conforms to specifications and fit to be used in manner for which it was designed, product-based quality emphasis on the increased student learning produced by the curriculum and academic staff, value-based quality encompasses an acceptable performance at an acceptable price, and user-based quality embedded quality like meeting students' needs, wants, and preferences.

Abdukarim and Ali (2012) were of the view that adequacy of instructional materials and facilities, quality of adult literacy facilitators in terms of competency and behavior, work load, methods of teaching and gender of the participants are some of the factors responsible for the persistence or non-persistence of adult most especially in literacy program. Ouma and Munyua (2018) argued that instructors' working conditions in the area of provision of incentives like adequate infrastructural facilities, teaching and learning resources and professional development among others are necessary conditions in ensuring effective discharge of their duties. Hence, poor working conditions and inadequate teaching and learning materials may de-motivate instructors from discharging their duties which may in turn adversely affect adults' participation rate into educational program. Kaume-Mwinzi (2018) acknowledged that teaching methods which are currently in use in some of the academic institutions are mainly teacher-centered despite the fact that the best teaching methods for the 21 st century learners are studentcentered. Oviawe (2017) suggested that creating awareness vis-à-vis orientations, career talk/week, seminars, role playing and media as well as admonish stakeholders to permit learners to take decisions on their own based on their interest and aptitude on what course or program to choose would foster learners enrolment into program like Technical Adult Education activities. Lase et al. (2018) submitted that parents' income level, parental education level, peer environment and self-efficacy are some of the predictors of adult learners' interest to continue studying.

Teaching and learning environment, according to Boniface (2018) has the potential to determine the learners' level of interest, degree of motivation and level of commitment. Such that favorable environment coupled with students' interest would significantly predict enrolment, learning and persistence. The reason for this is that when a teaching and learning environment is favorable, the students are comfortable and likely to get much information compared to those who are uncomfortable. In addition, when a classroom is well furnished with physical facilities coupled with an appealing social and psychological climate, learners become attracted to and interested in the activities going on in such an environment. On the other hands, unfavorable environment may discourage learners 
by dampening their interest and morale which might lead to reduction in the number of learners' enrolment and persistence in the program. This is consequent upon the fact that the decision by adult learners to exert extra effort and engage in any academic engagement is a function of the level of interest as well as other prevailing motivational instances put in motion by the educational environment.

Psychologically, participation may be seen as an outcome of a disposition towards available educational program. Though, the link between adults' disposition and behavior may not always necessarily direct. This is because, behavior is the outcome of an intention towards such a behavior. This intention may be a function of attitudinal traits (beliefs and evaluation of the behavior) and normative considerations (beliefs of other and motivation to comply with these beliefs). Hence, differences in dispositions, such as intention, attitude, and (perceived) needs may be accounted for differences in interest to participate into sandwich adult educational program. Furthermore, the intention of adult to enrolment into educational program may be in part as a result of the fact that the more the brain is used for academic task, the less likely cognitive function will be lost. This compliment the concept of use it or lose it, such that intelligence can actually increase with increased intellectual exercise. Non-enrolment and non-persistence of adult in the lifelong learning program, according to Laal (2011) may be attributed to factors like poor health, absence of a companion, fear of competition with others, fear of exposure of their background, fear of the unknown and location. Besides, status of adult learners towards the availability and qualification for incentives like scholarships, bursaries, and grants in aids coupled with previous result obtained may instigate them to participate and retain in the system. In the same vein, Papaioannou (2014) opined that lack of self-confidence, lack of external learning incentives (such as scholarship, bursary etc.), barriers to learning (like multiple problems, multiple roles, lack of time, biological/physical barriers, lack of memory, unable to concentrate, undiagnosed learning difficulties, burnout), lack of a learning culture and trouble in expressing oneself in writing or/and speaking may prevent adult from participating in educational programs.

On economic point of view, investments in education is seen as being beneficial because they will increase productivity and simultaneously individual welfare (both monetary and non-monetary). However, these investments entail direct and indirect costs (e.g., tuition fees, travel expenses, and opportunity costs) as well. So ultimately, individuals would wish to participate in adult education program provided perceived benefits outweigh perceived costs. The way costs and benefits are perceived would depend on factors like individual background attributes (age, gender, social economic status), employment characteristics (employment status, occupation, earnings), and societal variables (GDP per capita, unemployment rate). In developing nations like Nigeria, according to Wanjana and Otieno (2010) demand for education is considered by individuals and their relatives as a means to better income. In the light of this, Balami and Sakir (2014) acknowledged that increase in income would have significant influence on adult learners' enrolment into open and distance learning institutions. With regard to job advancement, Raabe et al. (2007) argued that all things being equal, adult with a specific and realistic career plan towards enrolment into educational program are more likely to be satisfied with their careers and vice-versa. With respects to age, adult enrolment in educational activities according to Kyndt et al. (2011) may tend to decrease with increasing age (most especially above 45) because as adults approach retirement phase, not only do they perceive less advantages coming from education to their professional progression, but they experience less support from their employers as well. In another development, Bye et al. (2007) pointed out that being older does not mean being less keen to knowledge and education, this is because according to them that non-traditional age undergraduates (above 25) have higher levels of intrinsic motivation than younger, traditional age undergraduates.

It is clear to infer that there is no consensus in the literature with respect to the factors responsible for adults' participation into educational programs. Even, none of these previous works direct attention towards adults participating in the sandwich educational program in Osun State. It is against this background that the study is designed to examine the psychosocial and economic variables as correlates of adults' participation into Sandwich educational programs in Osun state, Nigeria in order to fill the pertinent gap identified in the literature.

\subsection{Statement of the Problem}

In the recent past, there was an increase in the number of study centers across the states in Nigeria. In Osun state for instance, sandwich programs most especially National Teachers Institute study centers cropped up in many cities among which are; Ikire, Ede, Iwo etc. for postgraduate, undergraduate and Nigeria Certificate in Education programs. Observations across centers indicated that enrolment figure on the basis of departments in each of these study centers revealed that each of these centers had less than its required enrolment capacity when comparing with the human and physical capital resources available in each of the study center. Besides, it was also observed that some out of the few ones who enrolled into their first year program exited towards the commencement of the first semester examination for varieties of reasons which comprised psychological, societal and economic factors. Hence, the study is planned to examine psychosocial and economic variables as correlates of adults' participation into sandwich programs in Osun state, Nigeria.

\subsection{Objectives of the Study}

The broad objective of the study was to examine the psychosocial and economic variables as correlates of adults' participation into sandwich programs in Osun state, Nigeria. While the specific objectives are to;

i. examine the extent to which psychological factors influence adult participation into sandwich educational programs in Osun state;

ii. evaluate the societal variables' role in the determination of adults' participation into sandwich educational programs in Osun state; and

iii. ascertain the extent to which economic factors affect adults' participation into sandwich educational programs in Osun state.

The following research questions are raised to serve as guide for the study as thus; 
To what extent do psychological factors influence adults' participation into sandwich educational programs in Osun state?

ii. What roles do societal variables play in adults' participation into sandwich educational programs in Osun state?

iii. To what extent do economic factors affect adults' participation into sandwich educational programs in Osun state?

\subsection{Research Hypotheses}

The following hypotheses are highlighted and tested.

i. $\quad \mathrm{H}_{0}$ : there is no significant different in the extent to which psychological, societal and economic variables influence adults' participation into sandwich educational programs in Osun state on the basis of gender.

ii. $\quad \mathrm{H}_{0}$ : there is no significant different in the extent to which psychological, societal and economic variables influence adults' participation into sandwich educational programs in Osun state on the basis of employment status.

\subsection{Theoretical Framework}

\subsubsection{Maslow's Motivational Theory}

Maslow's theory of motivation was relevant in this research work. The theory postulates that human needs were in hierarchical order such that a person requires to satisfy these needs one level at a time, starting at the bottom of the hierarchy with basic needs and then moving upwards to satisfy needs of increasing levels of importance. These levels according to Gboku and Lekoko (2007) comprise physiological needs, that is, the basic needs that sustain life which entails items like food, water, sleep, sex, shelter, health and warmth; safety needs is the next to physiological needs which aimed at attaining a stable environment that is free from danger, threat, and fear of losing employment or property; followed by affiliation or love or acceptance needs which are to do with affection, a sense of belonging, and status; immediately after meeting the affiliation or love or acceptance needs, esteem needs follows which entail the need for self-respect, self-esteem and the esteem of others, and which lead to power, prestige, status, and self-confidence; and finally, self-actualization needs encompass the maximization of personal potential, self-fulfillment and accomplishment of life dreams. However, once the basic needs are fulfilled, then, the adults may begin to think of moving upwards to satisfy needs of increasing levels of importance which may include participation in the educational programs. The arrangement put forward by this theorist ignores individual level of determination towards his/her engagement in the exercise most especially sandwich educational programs.

\subsection{Self-Determination Theory}

Self-determination theory was propounded by Deci and Ryan (1985). The proponents stated that people are active organisms, with the growing tendencies geared towards mastering ambient challenges, and integrating new experiences into a coherent sense of self. They stressed that these natural development tendencies do not operate automatically, but rather requires on-going social nutriments and supports. According to them, the social context can either support or thwart the natural tendencies towards active engagement and psychological growth. Furthermore, the social context can catalyze to lack of integration, defense, and fulfillment of need-substitutes. The proponents remarked that the dialectic between the active organism and the social context is the basis for predictions about behavior, experience, and development. However, self-determination theory was adequate to this study, based on the fact that individuals or groups (most especially adults) need to be self-determined to achieve a set goal in the areas of their participation and learning at sandwich educational program. This is because, goal setting according to Stanford and Connie (2009) may influence the ways adults approach various types of barriers in life. Such that, ceteris paribus, adult are more likely to achieve their set goals not only that if their goals are specific and well-grounded, but also with self-determination towards all the educational exercises.

\section{Methodology}

\subsection{Research Design}

The study employed descriptive survey research design which is ex-post-facto in nature. This is premised on the fact that survey research design is generally conceived as one in which a group of people or items is studied by collecting and analysing data from only a few people or items considered to be representative of the entire target group (Nworgu, 2006). The design was considered appropriate because the researcher described the situation that exist and didn't manipulate the variables of the study.

\subsection{Population of the Study}

All adult learners who enrolled into undergraduate and postgraduate sandwich educational programs organized by National Teachers Institutes (NTI) and situated in Irewole Local Governments Area of Osun State formed the basis for target population.

\subsection{Sample and Sampling Technique}

Stratified random sampling technique was employed to select the sample of one-hundred and eight (108) participants from both undergraduate and postgraduate classes during 2018/2019 academic calendar. Strata was created not only on the basis of the department the participants belong to but also on academic phases/levels in their respective programs. The beauty of this technique was that it gave equal chance to all the participants of being involved in the exercise. 


\subsection{Instrumentation}

Quantitative instrument tagged Psychosocial and Economic Variables Questionnaire (PEVQ) was used. This was in four sections. Section A contained demographic characteristics of the respondents, and the remaining sections entailed items on psychosocial and economic factors as its influence adults' participation into sandwich educational programs.

\subsection{Validity and Reliability of the Instrument}

The content validity of the instrument was done by comparing each of the items included in the instrument with the objectives and research questions enumerated in the study. On the face validity, the researcher ensures that the items are worded and typed in a clear and concise form. For reliability of the instrument, the same instrument was administered on forty (40) respondents participated in other sandwich educational program. Cronbach technique was used to test the reliability of the instrument which produced 0.82 . This indicated that the instrument was consistent, suitable, reliable and appropriate for the study.

2.6. Method of Data Analysis

The study used both descriptive and inferential statistics to analyze the data generated from the field. Descriptive statistics was employed for the attainment of research objectives. While, independent t-test was used to test all the research hypotheses at $5 \%$ level of significance.

\section{Findings of the Study}

\subsection{Analysis Based on Research Questions}

Research Question I: To what extent do psychological factors influence adults' participation into sandwich educational programs?

Table-1. Descriptive analysis of the participants' opinion towards psychological variables.

\begin{tabular}{|c|c|c|c|c|c|}
\hline Items & VHE & $\mathrm{HE}$ & ME & LE & VLE \\
\hline Procrastination for participation in the program & $53(49.1 \%)$ & $20(18.5 \%)$ & $19(17.6 \%)$ & $4(3.7 \%)$ & $12(11.1 \%)$ \\
\hline $\begin{array}{l}\text { Phobia for academic related activities such as } \\
\text { examinations, tests, class presentation. }\end{array}$ & $14(13.0 \%)$ & $43(39.8 \%)$ & $23(21.3 \%)$ & $9(8.3 \%)$ & $19(17.6 \%)$ \\
\hline Lack of interest to participate & $7(6.5 \%)$ & $16(14.8 \%)$ & $24(22.2 \%)$ & $27(25.0 \%)$ & $34(31.5 \%)$ \\
\hline Lack of self confidence in academic task & $5(4.6 \%)$ & $11(10.2 \%)$ & $30(27.8 \%)$ & $22(20.4 \%)$ & $40(37.0 \%)$ \\
\hline Fear of criticism during teaching-learning process & $4(3.7 \%)$ & $23(21.3 \%)$ & $24(22.2 \%)$ & $27(25.0 \%)$ & $30(27.8 \%)$ \\
\hline $\begin{array}{l}\text { Endowment of natural ability to cope with academic } \\
\text { work }\end{array}$ & $23(21.3 \%)$ & $24(22.2 \%)$ & $20(18.5 \%)$ & $22(20.4 \%)$ & $19(17.6 \%)$ \\
\hline
\end{tabular}

Source: Field Work (2019).

Legend: VHE (Very High Extent); HE (High Extent); ME (Moderate Extent); LE (Low Extent); and VHE (Very Low Extent).

Table 1 indicated that ninety two (92) out of one-hundred and eight (108) respondents which accounted for 85.2 per cent of the participants have had procrastination tendency towards participation into sandwich educational program. On the part of phobia, 74.1 per cent of them were of the view that they had phobia to high, very high and moderate extent for all sort of academic related activities such as examinations, tests, class presentations, assignments, etc., In another development, majority of them shown interest to participate as more than half of the participants that is 56.5 per cent, 57.4 per cent, 52.8 per cent, 60.2 per cent and 61.1 per cent claimed that lack of interest, lack of self-confidence, fear of criticism, lack of concentration and fear of engaging in academic related competition with others respectively exert minimal effect on their participation. While, 62 per cent of the participants which is majority opined that their participation was premised on the endowment of natural ability to cope with academic task.

Research Question II: What role do societal variables play towards adults' participation into sandwich educational programs?

Table-2. Descriptive analysis of the participants' notion towards societal variables.

\begin{tabular}{|c|c|c|c|c|c|}
\hline $\mathbf{S} / \mathbf{N}$ & Statement & VS & $\overline{\mathbf{S}}$ & $\overline{\mathbf{U S}}$ & VUS \\
\hline 1 & Organization of learning resources & $62(57.4 \%)$ & $30(27.8 \%)$ & $16(14.8 \%)$ & $\mathrm{O}(\mathrm{O} \%)$ \\
\hline 2. & Level of awareness about the program & $20(18.5 \%)$ & $77(71.3 \%)$ & $8(7.4 \%)$ & $3(2.8 \%)$ \\
\hline 3. & Attitude of the facilitators & $46(42.6 \%)$ & $38(35.2 \%)$ & $15(13.9 \%)$ & $9(8.3 \%)$ \\
\hline 4. & Multiple roles e.g. family, student e.tc & $20(18.5 \%)$ & $51(47.2 \%)$ & $27(25.0 \%)$ & $10(9.3 \%)$ \\
\hline 5. & $\begin{array}{l}\text { Prevailing societal support such as scholarship, } \\
\text { grants etc. }\end{array}$ & $13(12.0 \%)$ & $31(28.7 \%)$ & $28(25.9 \%)$ & $36(33.3 \%)$ \\
\hline
\end{tabular}

Source: Field Work (2019).

Legend: VS (Very Satisfied); S (Satisfied); US (Unsatisfied); and VUS (Very Unsatisfied).

Table 2 revealed that the majority of the participants supported the assertions that learning resource was adequately organized, level of awareness about the availability of the program under consideration was satisfactory, attitude of the instructors or change agents towards adults in the study center was encouraging, prevailing multiple role such as parent, student, employer, employee etc., played insignificant roles in their satisfactory level, weak financial support by the society such as unavailability of scholarships and provision of educational grants for the caliber of students attending sandwich programs, ambient environment for teaching-learning interactions and 
other academic related task for those involving in practical related courses like Physical and Health Education (PHE), as well as satisfied with the location of the program as claimed by 85.2 per cent, 89.9 per cent, 77.8 per cent, 65.7 per cent, 59.2 percent, 66.7 per cent and 81.4 per cent of the entire respondents used in the study. Hence, it is indicated that adults' participation into sandwich educational program is a function of their level of satisfaction originate from societal indicators.

Research Question III: To what extent do economic factors affect adults' participation into sandwich educational programs?

Table-3. Descriptive analysis of the participants' view towards economic variables

\begin{tabular}{|c|c|c|c|c|c|}
\hline Statement & VHE & $\mathrm{HE}$ & ME & LE & VLE \\
\hline $\begin{array}{l}\text { Job enhancement in terms of promotion, productivity } \\
\text { etc. }\end{array}$ & $59(54.6 \%)$ & $11(10.2 \%)$ & $15(13.9 \%)$ & $12(11.1 \%)$ & $11(10.2 \%)$ \\
\hline $\begin{array}{l}\text { Level of financial resources required by the program } \\
\text { e.g. School fees, transportation expenses etc. }\end{array}$ & $11(10.2 \%)$ & $36(33.3 \%)$ & $33(30.6 \%)$ & $7(6.5 \%)$ & $21(19.4 \%)$ \\
\hline Increase in the level of income & $22(20.4 \%)$ & $19(17.6 \%)$ & $19(17.6 \%)$ & $31(28.7 \%)$ & $17(15.7 \%)$ \\
\hline Attainment of career plan or professional standard & $30(27.8 \%)$ & $25(23.2 \%)$ & $31(28.7 \%)$ & $19(17.6 \%)$ & $3(2.8 \%)$ \\
\hline $\begin{array}{l}\text { Qualification for an appointment such as head teachers, } \\
\text { principal, Head of Department, etc. }\end{array}$ & $33(30.6 \%)$ & $34(31.5 \%)$ & $24(22.2 \%)$ & $10(9.3 \%)$ & $7(6.4 \%)$ \\
\hline
\end{tabular}

principal, Head of Department, etc.

Legend: VHE (Very High Extent); HE (High Extent); ME (Moderate Extent); LE (Low Extent); and VHE (Very Low Extent).

Table 3 depicted that 78.7 per cent of the participants supported that job enhancement in terms of promotion facilitate their participation into sandwich educational program, 74.1 per cent of them were of the view that ability to avoid all forms of financial commitment associated with the program stimulate them to participate. 55.6 per cent acknowledged that their participation at sandwich program was to some extent necessitated by increase one level of income, 79.7 per cent agreed that attainment of career plan or professionalized their career encouraged them to to participate in the program while 84.3 per cent said that their participated was subjected to be qualified for duty post like headmasters at primary school level, principle or vice-principal for secondary as well as head of department at tertiary institution to mention a few.

3.2. Analysis Based on Research hypotheses

Research Hypothesis I: $\mathrm{H}_{0}$ : there is no significant different in the extent to which psychological, societal and economic variables influence adults' participation into sandwich educational programs on the basis of gender.

Table-4. T-test outcomes of the psychological, societal and economic variables on the basis of gender.

\begin{tabular}{|c|c|c|c|c|c|c|c|c|}
\hline Gender & Number & Variables & Mean & S.D & T-Cal & D.F & T-Tab & Remark \\
\hline Female & 35 & \multirow[t]{2}{*}{ Psychosocial } & 20.11 & 5.41 & \multirow[t]{2}{*}{1.82} & \multirow{5}{*}{106} & \multirow{5}{*}{1.98} & Insignificant \\
\hline Male & 73 & & 22.21 & 6.00 & & & & \\
\hline Male & 73 & Societal & 19.78 & 3.01 & 2.97 & & & Significant \\
\hline Female & 35 & \multirow[t]{2}{*}{ Economic } & 17.20 & 4.68 & \multirow[t]{2}{*}{0.03} & & & \multirow[t]{2}{*}{ Insignificant } \\
\hline Male & 73 & & 17.23 & 3.44 & & & & \\
\hline
\end{tabular}

Source: Field Work (2019). Two-tailed Test at $5 \%$ Level of Significance.

Table 4 revealed that there was no significant difference in the extent to which psychological variables such as procrastination to enroll, level of phobia for academic related task, interest among others influence adults' to participate into sandwich educational programs on the basis of gender. This is because, the calculated t-value is less than t-tabulated value (that is $1.82<1.98$ ). Hence, the null hypothesis was upheld. On the societal variables, it showed that there was significant difference in the role the societal variables like organization of learning resources, level of awareness, multiple role-family, student to mention a few played towards enrolment on the basis of gender. This indicated that female participants were not only satisfied with the prevailing societal factors but all attracted with it than their male counterparts. In the light of this, null hypothesis is rejected as the calculated tvalue is greater than t-tabulated value (that is $2.97>1.98$ ). Also, the findings revealed that there was no significant difference in the extent to which economic variables like job enhancement, financial commitment, monetary benefit, and attainment of professional standard influence both gender (female and male) to participate in the educational programs.

Research Hypothesis II: $\mathrm{H}_{0}$ : there is no significant different in the extent to which psychological, societal and economic variables influence adults' participation into sandwich educational programs on the basis of employment status.

Table-5. T-test outcomes of the psychological, societal and economic variables on the basis of employment status.

\begin{tabular}{|c|c|c|c|c|c|c|c|c|}
\hline Occupational Status & Number & Variables & Mean & S.D & T-Cal & D.F & T-Tab & Remark \\
\hline Employed & 72 & \multirow[t]{2}{*}{ Psychosocial } & 21.90 & 5.80 & \multirow[t]{2}{*}{0.79} & \multirow{6}{*}{106} & \multirow{6}{*}{1.98} & Insignificant \\
\hline Unemployed & 36 & & 20.94 & 6.00 & & & & \\
\hline Employed & 72 & \multirow[t]{2}{*}{ Societal } & 20.36 & 3.03 & \multirow[t]{2}{*}{0.21} & & & \multirow[t]{2}{*}{ Insignificant } \\
\hline Unemployed & 36 & & 20.22 & 3.40 & & & & \\
\hline Employed & 72 & \multirow[t]{2}{*}{ Economic } & 17.56 & 3.82 & \multirow[t]{2}{*}{1.12} & & & \multirow[t]{2}{*}{ Insignificant } \\
\hline Unemployed & 36 & & 16.67 & 3.94 & & & & \\
\hline
\end{tabular}

Source: Field Work (2019). Two-tailed Test at $5 \%$ Level of Significance.

Table 5 indicated that there was no significant different in the extent to which psychological, societal and economic variables influence adults' participation into educational programs on the basis of employment status of 
the participants. This is supported with empirical outcomes in which the calculated values of 0.79 , 0.21 and 1.12 which were higher than tabulated value of 1.98. Therefore, null hypothesis which says that there is no significant different in the extent to which psychological, societal and economic variables influence adults' participation into sandwich educational programs on the basis of employment status of the participants was upheld. This reflected that the extent to which these variables determine the level or decision to participate was insignificant of whether one is gainfully employed or not.

\section{Discussion and Recommendations}

On the psychological variables, the empirical outcomes revealed that the adults' participating in sandwich educational exercises had some forms of psychological manifestations like procrastination tendency towards enrolment, phobia for academic or academic related exercise such as examinations, tests, class presentations, and assignments. They showed endowment of natural ability and interest to participate at varying degree. This could be attributed to the presence of internal locus of control among adults which in part enhance them to adapt to any challenges that come their way in the course of teaching-learning process in terms of withstanding all forms of academic rigor in the system. This is in consonance with empirical finding reported by Balami and Sakir (2014) in which majority of the participants were of the view that their enrolment into open and distance learning programs was to attain psychological satisfaction.

With respect to societal variables, the findings indicated that the adults were satisfied with prevailing societal indices and opined that learning resource was adequately organized, level of awareness about the availability of the program under consideration was satisfactory, attitude of the instructors or change agents towards them was adequate, multiple role such as parent, student, employer and employee had nothing to do with their satisfactory level. Also, weak financial support in terms of unavailability of scholarships and education grants for the caliber of students attending sandwich educational programmers either on the part of government or private individuals. Besides, they acknowledged the availability of the ambient environment for teaching-learning interactions and other academic related task for those involving in practical related courses like Physical and Health Education (PHE), as well as suitable location of the program. Abdukarim and Ali (2012) corroborated this by identifying factors like gender roles, instructors' incompetence, inadequacy of instructional materials and its quality to mention a few as those responsible for adults' dropout from literacy programs in Nigeria. Similarly, it was in tandem with submission made by Sogunro (2015) in which quality of instruction; quality of curriculum; relevance and pragmatism; interactive classrooms and effective management practices; progressive assessment and timely feedback; self-directedness; conducive learning environment; and effective academic advising practices were pointed out as prominent motivating factors that facilitate adult learners' participation into higher education.

In terms of economic variables, the empirical outcomes supported that job enhancement vis-a-vis promotion, ability to avoid all forms of financial commitment associated with the program, increase level of income and attainment of career ladder or professionalization of the occupation facilitate would in part facilitate adults to participate into sandwich educational program. This is in line with empirical finding reported by Balami and Sakir (2014) in which economic reasons like moving upward one salary grade level from the terminal bar, increasing monthly salary and securing a job influence adults' participation into open and distance learning program.

On the hypotheses, the findings revealed that there was no significant difference in the extent to which psychological variables such as procrastination to enroll, level of phobia for academic related task, interest among others influence adult learners to participate into sandwich educational programs on the basis of gender. This is supported by Vakoufari et al. (2018) in which no statistically significant differences between the psychological variables like self-esteem, loneliness and intention for academic drop out in relation to the participants' demographic characteristics most especially gender was acknowledged. On the societal variables, it showed that there was significant difference in the societal variables like organization of learning resources, level of awareness, multiple role as family and student played on the basis of gender. This means that societal variables are in most cases favorable to female adults to enroll into sandwich educational programs than their male counterparts due to their financial commitments.

Besides, the findings also revealed that there was no significant difference in the extent to which economic variables like job enhancement, financial commitment, monetary benefit and attainment of professional standard influence both gender (female and male) to participate into sandwich educational programs. Furthermore, it indicated that there was no significant different in the extent to which psychological, societal and economic variables influence adult participation into sandwich educational programs on the basis of employment status. This reflected that the extent to which these variables determine the level or decision to participate was insignificant of whether one is gainfully employed or not. This could be attributed to the fact that very handful of them who were not gainfully employed as at the time of enrolment were involved in any of the empowerment programs which enable them to compete favorable with their counterparts and meet all financial commitments packaged within the purview of the programs. In general, the outcomes of this research work was in consonance with the psychosocial interactive model postulated by Darkenwald and Merriam (1982) in which a sequence of interactive variables such as; early individual and family characteristics; preparatory education and socialization; socio-economic status; learning pressure-the extent to which current social or working environment requires or encourages further learning; perceived values/utility of the program, readiness to participate; and specific stimuli were identified as predictive factors that responsible for participation or non-participation into adult education programs. In the same vein, González-Raimundí (2015) acknowledged that adult programs may provide that population the learning experiences that will capacitate them as professionals, as well as human beings. Based on the findings of this study, the following recommendations are suggested for concern stakeholders.

i. $\quad$ Adults should learn how to manage different psychological traits such as phobia and procrastinations that may be conflictual to their decisions to participate in the educational activities regardless of gender quality and occupational status. 
ii. Centre managers of the sandwich educational programs should as a matter of duty always employ bottom-up approach whenever the policy that relate to such program is to be formulated at the study center level. As this will give the adults sense of belonging.

iii. Government should make a financial means in terms of scholarship, bursary, matching grant and soft loan with moderate or without interest for both potential and existing adults who could not meet up with the financial responsibility ascribed for the educational program regardless of gender attribute and occupational ground.

iv. Instructors or change agents should base their teaching-learning processes on the assumptions of andragogy rather than pedagogy principles.

\section{References}

Abdukarim, I. and A. Ali, 2012. Adult learners dropout from literacy programmes in Gombe State, Nigeria: Implications for achievement of MDGS and EFA goals in Nigeria. Developing Country Studies, 2(9): 23-29.

Abdullah, M.M.B., S.F. Koren, B. Muniapan, B. Parasuraman and B. Rathakrishnan, 2009. Adult participation in self-directed learning programs. International Education Studies, 1(3): 66-72.

Balami, Y.G. and A. Sakir, 2014. Determinants of adult learners enrolment into open and distance learning institutions in the North East, Nigeria. Journal of Education and Practice, 5(31): 58-63.

Boniface, U.E., 2018. Classroom environment and academic interest as correlates of achievement in senior secondary school Chemistry in Ibadan South West local Government Area, Oyo State, Nigeria. Global Journal of Educational Research, 17(1): 61-71.Available at: https://doi.org/10.4314/gjedr.v17i1.9.

Bye, D., D. Pushkar and M. Conway, 2007. Motivation, interest, and positive affect in traditional and nontraditional undergraduate students. Adult Education Quarterly, 57(2): 141-158.Available at: https://doi.org/10.1177/0741713606294235.

Darkenwald, G.G. and S.B. Merriam, 1982. Adult education: Foundations of practice. New York: HarperCollins Publishers. pp: 260.

Deci, E.L. and R.M. Ryan, 1985. Intrinsic motivation and self-determination in human behaviour. New York: Plenum.

Gboku, M. and N.R. Lekoko, 2007. Developing programmes for adult learners in Africa. African perspective on adult learning series. Cape Town: Pearson Education and UNESCO.

González-Raimundí, Z., 2015. A phenomenological study of adult college student experience in nontraditional education programmes. International Journal of Educational Excellence, 1(1): 43-76.Available at: https://doi.org/10.18562/ijee.2015.0002.

Kasworm, C., 2003. Adult meaning making in the undergraduate classroom. Adult Education Quarterly, 53(2): 81-98.Available at: https://doi.org/10.1177/0741713602238905.

Kaume-Mwinzi, R.K., 2018. Teaching practices in the 21st century in Kenya: A qualitative approach. Educational Excellence, 4(1): 7999.Available at: https://doi.org/10.18562/ijee.034.

Kokkos, A., 2005. Adult learning. Investigating the domain. Athens: Metaixmio.

Koslowski, I.F.A., 2006. Quality and assessment in context: A brief review. Quality Assurance in Education, 14(3): 277-288.Available at: https://doi.org/10.1108/09684880610678586.

Kyndt, E., M. Michielsen, L. Van Nooten, S. Nijs and H. Baert, 2011. Learning in the second half of the career: Stimulating and prohibiting reasons for participation in formal learning activities. International Journal of Lifelong Education, 30(5): 681-699.Available at: https://doi.org/10.1080/02601370.2011.611905.

Laal, M., 2011. Barriers to lifelong learning. Procedia-Social and Behavioral Sciences, 28: 612-615.

Lase, I.P.S., I. Zul Azhar and H. Kampus, 2018. Factors influencing vocational students interest in district in continuing studies into universities. International Journal of Progressive Sciences and Technologies, 10(1): 201-208.

Nworgu, B.G., 2006. Educational research; basic issues and methodology. Ibadan: Wisdom Publisher Limited, State Hospital Road Ring Road.

Ouma, N.O. and J.K. Munyua, 2018. Relationship between teachers' working conditions and students' academic performance in public day secondary schools in Nyando Sub-County, Kenya. British Journal of Education, 6(5): 52-58.

Oviawe, J.I., 2017. Fostering students' enrolment in technical education programmes through career guidance and occupational awareness. Education Journal, 6(4): 125-132.Available at: https://doi.org/10.11648/j.edu.20170604.11.

Papaioannou, E., 2014. The empowerment of vulnerable adults through education. Peer Learning Activity II. Adult Teaching Sta Training. Renewed European Agenda for Adult Learning 2012-2014.

Raabe, B., M. Frese and T.A. Beehr, 2007. Action regulation theory and career self-management. Journal of Vocational Behavior, 70(2): 297311.Available at: https://doi.org/10.1016/j.jvb.2006.10.005.

Rogers, A. and N. Horrocks, 2010. Teaching adults. 4th Edn., United Kingdom: Open University Press, Milton Keynes McGraw-Hill International.

Sogunro, O.A., 2015. Motivating factors for adult learners in higher education. International Journal of Higher Education, 4(1): 22-37.

Stanford, T.G. and M. Connie, 2009. Psychology of success: Overcoming barriers to pursuing further education. The Journal of Continuing Higher Education, 57(1): 10-21.Available at: https://doi.org/10.1080/07377360902810744.

Train Intercultural Mediators for a Multicultural Europe Project Partnership, 2016. Self-study course for trainers of intercultural mediators: Adult training methodology and techniques, developed and edited by Olympic Training and Consulting Ltd. Available from www.olympiakokek.gr.

Vakoufari, M., C. Angela and I. Mavroidiski, 2018. Self-esteem and loneliness as factors affecting distance learning students. European Journal of Open, Distance and E-Learning, 17(2): 100-116.

Wanjana, G. and D.O. Otieno, 2010. Factors influencing demand for bachelor of education degree by distance learning at the University of Nairobi. Journal of Continuing, Open and Distance Education, 1(1): 3-8.

Wlodkowski, R.J., 2003. Fostering motivation in professional development programs. New Directions for Adult and Continuing Education, 98: 39-48.Available at: https://doi.org/10.1002/ace.98. 